\title{
COPD and cognitive impairment: the role of hypoxemia and oxygen therapy
}

This article was published in the following Dove Press journal: International Journal of Chronic Obstructive Pulmonary Disease 9 August 2010

Number of times this article has been viewed

\section{Neeta Thakur' \\ Paul D Blanc ${ }^{2}$ \\ Laura J Julian' \\ Edward $\mathrm{H}_{\text {Yelin }}^{3}$ \\ Patricia P Katz ${ }^{3}$ \\ Stephen Sidney ${ }^{4}$ \\ Carlos Iribarren ${ }^{4}$ \\ Mark D Eisner ${ }^{1,2}$}

'Department of Medicine, ${ }^{2}$ Division of Occupational and Environmental Medicine and Division of Pulmonary and Critical Care Medicine, ${ }^{3}$ Institute for Health Policy Studies, Department of Medicine, University of California, San Francisco, CA, USA, ${ }^{4}$ Division of Research, Kaiser Permanente, Oakland, CA, USA
Correspondence: Mark D Eisner

University of California,

505 Parnassus Ave, MI097,

San Francisco, CA 94|43-0।II, USA

$\mathrm{Tel}+$ I 4I5 476735 I

Fax +I 4I5 4766426

Email mark.eisner@ucsf.edu
Background: Several studies have shown an association between chronic obstructive pulmonary disease (COPD) and cognitive impairment. These studies have been limited by methodological issues such as diagnostic uncertainty, cross-sectional design, small sample size, or lack of appropriate referent group. This study aimed to elucidate the association between COPD and the risk of cognitive impairment compared to referent subjects without COPD. In patients with established COPD, we evaluated the impact of disease severity and impairment of respiratory physiology on cognitive impairment and the potential mitigating role of oxygen therapy.

Methods: We used the Function, Living, Outcomes and Work (FLOW) cohort study of adults with COPD $(n=1202)$ and referent subjects matched by age, sex, and race $(n=302)$ to study the potential risk factors for cognitive impairment among subjects with COPD. Cognitive impairment was defined as a Mini-Mental State Exam score of $<24$ points. Disease severity was using Forced Expiratory Volume in one second $\left(\mathrm{FEV}_{1}\right)$; the validated COPD Severity Score; and the BMI (Body Mass Index), Obstruction, Dyspnea, Exercise Capacity (BODE) Index. Multivariable analysis was used to control for confounding by age, sex, race, educational attainment, and cigarette smoking.

Results: COPD was associated with a substantive risk of cognitive impairment compared to referent subjects (odds ratio [OR] 2.42; 95\% confidence interval [CI] 1.043-6.64). Among COPD patients, none of the COPD severity measures were associated with the risk of cognitive impairment $(P>0.20$ in all cases). Low baseline oxygen saturation was related to increased risk of cognitive impairment (OR for oxygen saturation $\leq 88 \%$ (OR 5.45; 95\% CI 1.014-29.2; $P=0.048)$. Conversely, regular use of supplemental oxygen therapy decreased the risk for cognitive impairment (OR 0.14; 95\% CI 0.07-0.27; $P<0.0001$ ).

Conclusion: COPD is a major risk factor for cognitive impairment. Among patients with COPD, hypoxemia is a major contributor and regular use of home oxygen is protective. Health care providers should consider screening their COPD patients for cognitive impairment.

Keywords: chronic obstructive pulmonary disease

\section{Introduction}

Chronic obstructive pulmonary disease (COPD) is characterized by the irreversible loss of lung function. Although COPD has been traditionally considered as a disease primarily affecting the lungs, its systemic effects have been increasingly recognized with diverse manifestations involving body systems distant from the lung. ${ }^{1,2}$ The brain, in particular, may be vulnerable to the systemic effects of COPD. ${ }^{3-8}$ Several features of the disease may contribute to impaired cognitive function, including hypoxemia and comorbid cardiovascular disease..$^{7-9}$ In addition, COPD may lead patients to curtail their physical activity which may, in turn, further increase the risk of cognitive impairment. ${ }^{10}$ 
Although there is a plausible link between COPD and cognitive impairment, the existing literature is limited by methodological issues such as diagnostic uncertainty, crosssectional design, small sample size, or lack of appropriate referent group. ${ }^{11-14}$ In a large cohort study of COPD, we aimed to elucidate the impact of COPD on the risk of cognitive impairment compared to a matched referent group without disease. Among patients with established COPD, we evaluated the impact of disease severity and impairment of respiratory physiology on cognitive impairment and the potential mitigating role of oxygen therapy.

\section{Methods}

\section{Recruitment of the cohort and referent subjects}

The current study is a matched case-referent analysis conducted within the Function, Living, Outcomes, and Work (FLOW) study of COPD. The FLOW study is an ongoing prospective cohort study of adult members of an integrated health care delivery system with a physician's diagnosis of COPD with an accompanying matched control group. Recruitment methods have been previously reported in detail. ${ }^{1,15-17}$ We recruited a cohort of 1,202 Kaiser Permanente Medical Care Program (KPMCP) members who were recently treated for COPD using a validated algorithm based both on health care utilization and pharmacy dispensing for COPD. ${ }^{18}$ A control group of 302 subjects without COPD were recruited who were matched by age, sex, and race to the cohort members. Spirometry confirmed that none of the controls met Global Initiative for Chronic Obstructive Lung Disease (GOLD) criteria for COPD. At baseline assessment, we conducted structured telephone interviews that ascertained sociodemographic characteristics, COPD clinical history, and health status. ${ }^{1,15,16}$ Research clinic visits included spirometry, other physical assessments, and cognitive testing. The study was approved both by the University of California, San Francisco Committee on Human Research and the Kaiser Foundation Research Institute's institutional review board and all participants provided written informed consent.

\section{Structured telephone interviews}

All subjects (COPD subjects and non-COPD referents) underwent 30-40 minute structured telephone interviews that ascertained sociodemographic characteristics, cigarette smoking, health status, and home oxygen use. As in our previous studies, we defined educational attainment as high school or less, some college, or college/graduate degree. ${ }^{19}$ Race-ethnicity was categorized as white non-Hispanic,
African American, Asian/Pacific Islander, Hispanic, or other. ${ }^{19}$ Cigarette smoking was measured using questions developed for the National Health Interview Survey (NHIS) and was defined as current smoking, past smoking, or never smoked. ${ }^{20}$ We assessed comorbid cardiovascular conditions using survey items modified from the NHIS. ${ }^{21}$ These include a reported physician's diagnosis of coronary artery disease, congestive heart failure, or stroke based on our previous work. ${ }^{1}$

\section{Assessment of pulmonary physiology}

Baseline oxygen saturation was measured at rest in the seated position using the Nellcor N-180 (Covidien-Nellcor, Boulder, $\mathrm{CO}$ ). Most subjects were measured on room air; 61 subjects had oxygen saturation measured on their prescribed supplemental oxygen (range 1-4 liters/minute).

To measure pulmonary function, we conducted spirometry according to American Thoracic Society (ATS) Guidelines..$^{22,23}$ We used the EasyOne ${ }^{\mathrm{TM}}$ Frontline spirometer (ndd Medical Technologies, Chelmsford, MA, USA), which is known for its reliability, accuracy, and durability and has been widely used in epidemiologic research. ${ }^{24,25}$ Because research clinic examinations were conducted by trained nonmedical personnel, we did not administer bronchodilators for study purposes. However, $90 \%$ of subjects had taken their own short-acting bronchodilator within 4 hours of spirometry or had taken a long-acting bronchodilator earlier in the same day.

\section{Measurement of COPD severity}

We used a combined approach to measure COPD severity. We used a disease-specific COPD severity score that we had previously developed and validated for use in epidemiologic and outcomes research. ${ }^{26,27}$ Based on survey responses, the COPD severity score is comprised of five overall aspects of COPD severity: respiratory symptoms, systemic corticosteroid use, other COPD medication use, previous hospitalization or intubation for respiratory disease, and home oxygen use. Each item was weighted based on clinical aspects of the disease and its expected contribution to overall COPD severity. Possible total scores range from 0 to 35, with higher scores reflecting more severe COPD.

We also used the validated BMI (Body Mass Index), Obstruction, Dyspnea, Exercise Capacity (BODE) Index, which is a multi-modal measure of disease severity. ${ }^{28}$ The BODE Index is based on the body-mass index $(B)$, the degree of airflow obstruction $(O)$ measured by Forced Expiratory Volume in one second $\left(\mathrm{FEV}_{1}\right)$, grade of dyspnea $(D)$ assessed by the modified Medical Research Council (MRC) 
Dyspnea Scale, and exercise capacity $(E)$ measured by the six-minute-walk test. Each component is assigned a specific score and the total score ranges from 0 to 10 points (higher scores indicate greater severity). The BODE index predicts death and other poor outcomes in COPD. ${ }^{28-30}$

\section{Cognitive assessment}

At the time of the research clinic visit, cognitive function was measured using the Mini-Mental State Examination, which is the most commonly used screening test for cognitive impairment in North America. ${ }^{31}$ The 11 -item instrument assesses orientation, recall ability, short-term memory, and arithmetic ability. ${ }^{32}$ It evaluates most of the main domains of cognitive status and has been extensively validated. ${ }^{31-36}$ We used the recommended cut-point score of $<24$ points out of the total possible 30 points to indicate cognitive impairment. ${ }^{37}$

\section{Statistical analysis}

Statistical analysis was conducted using SAS software, version 9.1 (SAS Institute, Inc, Cary, NC, USA) and Stata 10 (College Park, TX, USA). Bivariate comparisons were carried out using $t$-test for continuous variables and the chi-square test for categorical variables. We used logistic regression analysis to examine the association between COPD (vs referent) and the risk of cognitive impairment, controlling for age, sex, race, educational attainment, and smoking history (past smoking and current smoking as indicator variables).

In the COPD cohort, we used multivariable logistic regression analysis to elucidate the association between COPD severity measures and the risk of cognitive impairment. Risk estimates (ie, odds ratios) were expressed per a 0.5 standard deviation of each predictor variable, an approximation of the minimal clinically important difference. ${ }^{38}$ Multivariable analysis was used to control for age, sex, race, educational attainment, and smoking history.

We also evaluated the impact of home oxygen use on the risk of cognitive impairment. Because oxygen therapy is prescribed to patients with more severe disease, confounding by indication will likely bias the unadjusted results in the direction of no effect. We used two approaches to control for confounding. First, we used standard multivariable logistic regression. Second, we used propensity scores to correct for confounding by indication. Propensity scores were developed from a multivariable logistic regression model to predict home oxygen use conditional on observed covariates. Variables included were age, sex, race, smoking history, BODE Score, $\mathrm{FEV}_{1}$, baseline oxygen saturation $(\leq 88 \%)$, and desaturation during Six Minute Walk Test ( $\geq 4 \%$ ). Area under receiver operator characteristic curve for this model was excellent (0.92). Multivariable logistic regression analysis was then used to evaluate the impact of home oxygen use on the risk of cognitive impairment using inverse probability-weighted estimators derived from the propensity scores to control for confounding. ${ }^{39}$

The LOWESS (locally weighted regression scatter plot smoother) procedure was used to graphically depict the relationship between oxygen saturation and the logit (ie, log odds) of cognitive impairment. This method fitted a flexible smoothed curve that did not impose a linear relationship. ${ }^{40}$

\section{Results \\ Baseline characteristics of subjects with and without COPD}

Subjects with and without COPD were similar in age, sex, and race-ethnicity, which reflected matching $(P>0.20$ in all cases) (Table 1). The prevalence of lifetime smoking was higher among those with COPD (87\%) than in the referent group (48\%) $(P<0.0001)$. Persons with COPD also had lower educational attainment than referents.

\section{COPD and the risk of cognitive impairment}

The prevalence of cognitive impairment was much higher among COPD subjects compared to the matched referent group without COPD (5.5\% vs $2.0 \%, P=0.0051)$. In multivariable analysis, COPD was associated with a greater risk of cognitive impairment function even after controlling for age, sex, race, smoking history, and educational attainment (OR 2.42, 95\% CI 1.043-6.64) (Table 2).

\section{Risk factors for cognitive impairment among subjects with COPD}

Among patients with COPD, respiratory impairment, as measured by $\mathrm{FEV}_{1}$, was not associated with cognitive impairment (Table 3 ). Low baseline oxygen saturation $(\leq 88 \%)$ was strongly related to cognitive impairment (adjusted OR 5.45; 95\% CI 1.014-29.2). A small minority of subjects $(n=61)$ used prescribed supplemental oxygen. When oxygen use was added to the multivariable model, low oxygen saturation remained associated with a greater risk of cognitive impairment (OR 5.46; 95\% CI 1.007-30). Figure 1 demonstrates that the risk of cognitive impairment increases with decreasing oxygen saturation, but that the relationship is non-linear. 
Table I Baseline characteristics of FLOW cohort of COPD vs referent subjects

\begin{tabular}{|c|c|c|c|}
\hline Characteristic & COPD $(n=1,202)$ & Referents $(n=302)$ & $P$-value \\
\hline Age in years, mean (SD) & $58.2(6.2)$ & $58.5(6.2)$ & 0.50 \\
\hline Female, n (\%) & 691 (57.4\%) & $185(61 \%)$ & 0.23 \\
\hline Race/ethnicity, n (\%) & & & 0.96 \\
\hline White, non-Hispanic & $810(67 \%)$ & $200(66 \%)$ & \\
\hline African-American & $206(17 \%)$ & 57 (19\%) & \\
\hline Asian/Pacific Islander & $35(3 \%)$ & $8(3 \%)$ & \\
\hline Hispanic & III (9\%) & $28(9 \%)$ & \\
\hline Other & $40(3 \%)$ & $9(3 \%)$ & \\
\hline Educational attainment, n (\%) & & & $<0.0001$ \\
\hline High school or less & 352 (29\%) & $42(14 \%)$ & \\
\hline Some college & $524(44 \%)$ & $95(31 \%)$ & \\
\hline College/graduate degree & $326(27 \%)$ & 165 (55\%) & \\
\hline Smoking status, n (\%) & & & $<0.0001$ \\
\hline Never smoked & $165(13 \%)$ & I 58 (52\%) & \\
\hline Current smoker & $393(33 \%)$ & $12(4 \%)$ & \\
\hline Ex-smoker & 644 (54\%) & I 32 (44\%) & \\
\hline
\end{tabular}

Abbreviations: COPD, chronic obstructive pulmonary disease; FLOW, Function, Living, Outcomes and Work; SD, standard deviation.

The risk of cognitive impairment was not associated with COPD severity as defined by either the COPD severity score or BODE score (Table 3). Stroke and other cardiovascular disease were also not related to cognitive impairment (Table 4).

\section{Home oxygen therapy and cognitive impairment in COPD}

Home oxygen therapy was associated with a decreased risk of cognitive impairment among persons with COPD (Table 5). The unadjusted estimate, which was likely confounded by indication, did not exclude the 'no effect' level. In the most adjusted model, using inverse probabilityweighted estimators derived from the propensity scores to control for confounding, home oxygen use was strongly associated with a decreased risk of cognitive impairment (OR 0.14; 95\% CI 0.01-0.27).

\section{Discussion}

COPD is often considered a disease that solely affects the lungs; however, its extrapulmonary effects are profound and disabling. Our study indicates that COPD is strongly associated with cognitive impairment in a large cohort of patients with a broad range of COPD severity. Resting hypoxemia was the single most important risk factor for cognitive impairment; treatment with supplemental oxygen markedly decreased the risk. Lung function impairment, COPD severity, and cardiovascular disease did not appear to explain the development of cognitive impairment in COPD.

We used a rigorous and multifaceted approach to measuring COPD severity (lung function, COPD Severity Score, and BODE Index). Despite this approach, we found no impact of these indicators of disease severity on the risk of cognitive impairment. This differs from some previous work, ${ }^{41}$ but is similar to other studies that found no association between disease severity and cognitive impairment. ${ }^{42}$ Our results reveal a disconnect between global measures of COPD severity, which were not related to cognitive impairment, and decreased resting oxygenation, which was strongly associated with decreased cognitive function.

The specific role of cardiovascular comorbidities as a risk factor for cognitive impairment in COPD is difficult to ascertain as both conditions share risk factors (eg, smoking) and COPD patients may be predisposed to cardiovascular events. ${ }^{18}$ When cardiovascular comorbidities were evaluated as a risk factor for cognitive impairment, no association was found among the COPD cohort. The point estimate for cardiovascular disease was elevated, however, in the unadjusted analysis, so lack of statistical power may be one explanation

Table 2 COPD and the risk of cognitive impairment

\begin{tabular}{lll}
\hline Comparison & $\begin{array}{l}\text { Unadjusted } \\
\text { OR }(95 \% \mathbf{~ C l})\end{array}$ & $\begin{array}{l}\text { Controlling for age, sex, race, educational } \\
\text { attainment, and smoking history OR (95\% Cl) }\end{array}$ \\
\hline Referent Group & 1.0 & 1.0 \\
COPD & $2.86(1.34-7.46)$ & $2.42(1.043-6.64)$ \\
\hline
\end{tabular}

Abbreviations: $\mathrm{Cl}$, confidence interval; $\mathrm{OR}$, odds ratio. 
Table 3 Relationship between COPD severity and cognitive impairment

\begin{tabular}{lll}
\hline Disease severity measure & \multicolumn{2}{l}{ Risk of cognitive impairment } \\
& $\begin{array}{l}\text { Unadjusted } \\
\text { OR }(95 \% \mathrm{CI})\end{array}$ & $\begin{array}{l}\text { Multivariable } \\
\text { OR }(95 \% \mathrm{CI}) \dagger\end{array}$ \\
\hline Forced expiratory volume in I & $0.97(0.85-\mathrm{I} . \mathrm{II})$ & $0.93(0.79-\mathrm{I} .09)$ \\
second* & $P=0.63$ & $P=0.35$ \\
Baseline oxygen saturation & $4.4 \mathrm{I}(0.92-2 \mathrm{I})$ & $5.45(\mathrm{I} .014-29.2)$ \\
$\leq 88 \%^{\ddagger}$ & $P=0.064$ & $P=0.048$ \\
BODE Score* & $\mathrm{I} .13(\mathrm{I} .002-\mathrm{I} .27)$ & $\mathrm{I} .08(0.95-1.23)$ \\
& $P=0.046$ & $P=0.25$ \\
COPD Severity Score* & $\mathrm{I} .08(0.94-\mathrm{I} .23)$ & $\mathrm{I} .03(0.90-1.17)$ \\
& $P=0.28$ & $P=0.66$
\end{tabular}

*odds ratio per $1 / 2$ standard deviation decrement.

tSeparate multivariable logistic regression analysis for each severity measure plus age, sex, race, educational attainment, and smoking history.

$¥ 61$ subjects had oxygen saturation measured on supplemental oxygen (range I-4 liters/minute). When oxygen use was added to the multivariable model, low oxygen saturation remained associated with a greater risk of cognitive impairment (OR 5.46; $95 \% \mathrm{Cl}$ I.007-30; $P=0.049$ ). In additional analysis, oxygen flow rate (no oxygen, flow $=0$ liters/minute) was added to the multivariable model with minimal impact on the results (OR $5.44 ; 95 \% \mathrm{Cl}$ I.008-29; $P=0.049$ ).

Abbreviations: BODE, BMI (Body Mass Index), Obstruction, Dyspnea, Exercise Capacity; $\mathrm{Cl}$, confidence interval; $\mathrm{COPD}$, chronic obstructive pulmonary disease; $\mathrm{OR}$ odds ratio.

for this lack of effect. Controlling for covariates, such as smoking, reduced the effect estimate, so that any association between cardiovascular disease and cognitive impairment may be mediated by smoking and other factors.

Cognitive impairment may interfere with patients' ability to adhere to their medication regimen, adjust their medications in response to respiratory symptoms, and perform other aspects of self-management. Given that many of the medications for COPD are self-activated, even mild degrees of cognitive impairment could have significant effects on

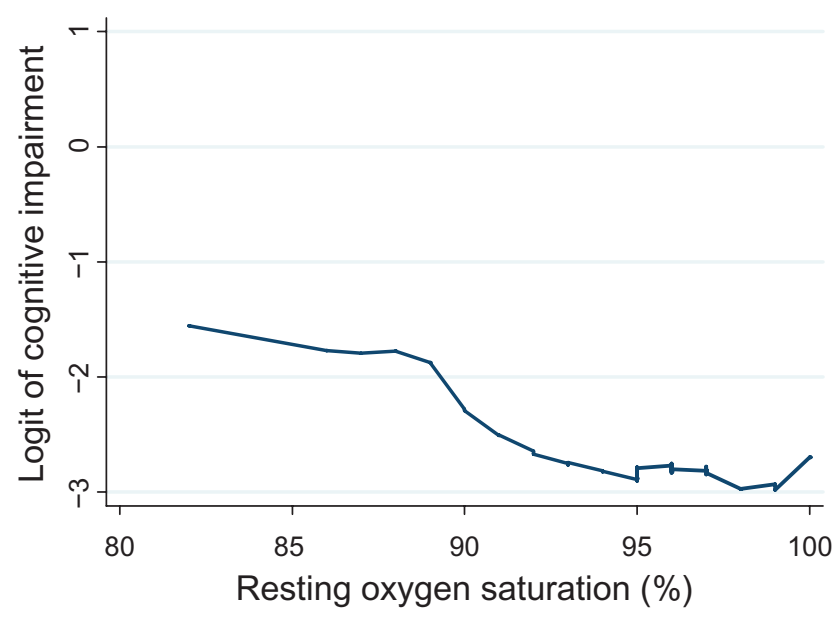

Figure I Relationship between resting oxygen saturation and the risk of cognitive impairment. Oxygen saturation was measured using pulse oximetry. The LOWESS (locally weighted regression scatter plot smoother) procedure was used to graphically depict the relationship between oxygen saturation and the logit (ie, log odds) of cognitive impairment. This method fitted a flexible smoothed curve that did not impose a linear relationship.
Table 4 Cardiovascular disease and the risk of cognitive impair-ment in COPD

\begin{tabular}{lll}
\hline Cardiovascular disease & \multicolumn{2}{l}{ Risk of cognitive impairment } \\
& $\begin{array}{l}\text { Unadjusted } \\
\text { OR }(95 \% \mathrm{Cl})\end{array}$ & $\begin{array}{l}\text { Multivariable } \\
\text { OR }(95 \% \mathrm{Cl}) \dagger\end{array}$ \\
\hline Stroke $(\mathrm{n}=68 ; 4.5 \%)$ & $0.8 \mathrm{I}(0.25-2.66)$ & $0.78(0.23-2.6 \mathrm{I})$ \\
& $P=0.73$ & $P=0.68$ \\
Other cardiovascular disease & $\mathrm{I} .57(0.92-2.69)$ & $\mathrm{I} .30(0.74-2.3 \mathrm{I})$ \\
$(\mathrm{n}=84 \mathrm{I} ; 56 \%)^{*}$ & $P=0.10$ & $P=0.36$ \\
\hline
\end{tabular}

*hypertension, coronary artery disease, or congestive heart failure.

tMultivariable logistic regression analysis including age, sex, race, educational attainment, and smoking history.

Abbreviations: $\mathrm{Cl}$, confidence interval; $\mathrm{OR}$, odds ratio.

disease management. More broadly, cognitive impairment may create difficulties with performing daily activities, especially those that involve memory or complex reasoning. ${ }^{43}$ It is likely that cognitive impairment has major effects on many aspects of patient functioning and health status.

The MMSE is a widely used measure of cognitive impairment but it is not sensitive for mild cognitive dysfunction. ${ }^{44,45}$ Consequently, our methods could have missed cases of mild cognitive impairment. It remains possible, therefore, that COPD severity could predict milder degrees of cognitive dysfunction. A future analysis of cognitive impairment using a detailed neuropsychologic battery of tests is required to evaluate milder cognitive impairment in COPD.

Our study is subject to several other limitations. Because our primary study focus was development of disability in COPD, we enrolled younger patients (45-65 years). Consequently, our study may underestimate the impact of COPD on cognitive impairment in older patients. Misclassification

Table 5 Home oxygen use and the risk of cognitive impairment in COPD

\begin{tabular}{ll}
\hline Statistical model & $\begin{array}{l}\text { Risk of cognitive impairment } \\
\text { OR }(95 \% \mathrm{CI})\end{array}$ \\
\hline Unadjusted & $0.74(0.26-\mathrm{I} .7 \mathrm{I})$ \\
& $P=0.53$ \\
Multivariable model* & $0.40(0.1 \mathrm{I}-\mathrm{I} .17)$ \\
& $P=0.1 \mathrm{I}$ \\
Multivariable model (propensity & $0.14(0.07-0.27)$ \\
score adjusted) $^{\dagger}$ & $P<0.000 \mathrm{I}$ \\
\hline
\end{tabular}

*Multivariable logistic regression analysis including home oxygen use plus age, sex, race, educational attainment, smoking history, baseline oxygen saturation, BODE Score, COPD Severity Score, FEV , $_{\text {, }}$ and height.

†Multivariable model including inverse probability-weighted estimators, which were derived from propensity scores. Propensity scores were developed from a separate multivariable logistic regression model to predict home oxygen use. Variables included were age, sex, race, smoking history, BODE Score, FEV ${ }_{1}$, and baseline oxygen saturation $(\leq 88 \%)$. Area under receiver operator characteristic curve for model was 0.92 . See Methods for more details.

Abbreviations: BODE, BMI (Body Mass Index), Obstruction, Dyspnea, Exercise Capacity; $\mathrm{Cl}$, confidence interval; $\mathrm{Cl}$, confidence interval; COPD, chronic obstructive pulmonary disease; $\mathrm{FEV}_{1}$, Forced Expiratory Volume in one second; OR, odds ratio. 
of COPD could also have occurred. Our COPD definition required concomitant treatment with COPD medications to increase the specificity of our definition. In addition, all patients had a physician diagnosis of COPD and reported having the condition. The lifetime smoking prevalence was similar to that in other population-based epidemiologic studies of COPD, supporting the diagnosis of COPD rather than asthma. ${ }^{46,47}$ We also previously demonstrated the validity of our approach using medical record review. ${ }^{18}$ Nonetheless, we acknowledge this potential limitation.

Another limitation is the small proportion of subjects who were using home oxygen. Consequently, the confidence intervals around our estimates of the effectiveness of oxygen for preventing cognitive impairment are wide in some cases. As the FLOW cohort continues longitudinal follow-up, we will further evaluate the impact of oxygen therapy on cognitive function.

COPD is a multisystem disease with extrapulmonary sequelae. It is strongly associated with an increased risk of cognitive impairment, especially among hypoxemic patients. Clinicians should evaluate their COPD patients for cognitive impairment in order to identify those who may benefit from interventions such as medication assistance or supplemental oxygen therapy. Future research should use detailed neuropsychological testing to carefully evaluate multiple cognitive domains among subjects with a broad range of ages and disease severity.

\section{Acknowledgment}

Funded by: NHLBI/NIH R01HL077618 and K24 HL 097245.

\section{Disclosure}

The authors report no conflicts of interest in this work.

\section{References}

1. Eisner MD, Blanc PD, Yelin EH, et al. COPD as a systemic disease: impact on physical functional limitations. Am J Med. 2008;121:789-796.

2. Rodriguez Gonzalez-Moro JM, de Lucas Ramos P, Izquierdo Alonso JL, et al. Impact of COPD severity on physical disability and daily living activities: EDIP-EPOC I and EDIP-EPOC II studies. Int $J$ Clin Pract. 2009;63:742-750.

3. Grant I, Prigatano GP, Heaton RK, McSweeny AJ, Wright EC, Adams KM. Progressive neuropsychologic impairment and hypoxemia. Relationship in chronic obstructive pulmonary disease. Arch Gen Psychiatry. 1987;44:999-1006.

4. Incalzi RA, Gemma A, Marra C, Muzzolon R, Capparella O, Carbonin P. Chronic obstructive pulmonary disease. An original model of cognitive decline. Am Rev Respir Dis. 1993;148:418-424.

5. Ozge C, Ozge A, Unal O. Cognitive and functional deterioration in patients with severe COPD. Behav Neurol. 2006;17:121-130.

6. Ortapamuk H, Naldoken S. Brain perfusion abnormalities in chronic obstructive pulmonary disease: comparison with cognitive impairment. Ann Nucl Med. 2006;20:99-106.
7. Heaton RK, Grant I, McSweeny AJ, Adams KM, Petty TL. Psychologic effects of continuous and nocturnal oxygen therapy in hypoxemic chronic obstructive pulmonary disease. Arch Intern Med. 1983;143: 1941-1947.

8. Krop HD, Block AJ, Cohen E. Neuropsychologic effects of continuous oxygen therapy in chronic obstructive pulmonary disease. Chest. 1973; $64: 317-322$.

9. Fillit H, Nash DT, Rundek T, Zuckerman A. Cardiovascular risk factors and dementia. Am J Geriatr Pharmacother. 2008;6:100-118.

10. Lautenschlager NT, Cox KL, Flicker L, et al. Effect of physical activity on cognitive function in older adults at risk for Alzheimer disease: a randomized trial. JAMA. 2008;300:1027-1037.

11. Hung WW, Wisnivesky JP, Siu AL, Ross JS. Cognitive decline among patients with chronic obstructive pulmonary disease. Am J Respir Crit Care Med. 2009;180:134-137.

12. Moss M, Franks M, Briggs P, Kennedy D, Scholey A. Compromised arterial oxygen saturation in elderly asthma sufferers results in selective cognitive impairment. J Clin Exp Neuropsychol. 2005;27: $139-150$.

13. Incalzi RA, Chiappini F, Fuso L, Torrice MP, Gemma A, Pistelli R. Predicting cognitive decline in patients with hypoxaemic COPD. Respir Med. 1998;92:527-533.

14. Ohrui T, Tanaka K, Chiba K, et al. Cognitive decline in patients with long-term domiciliary oxygen therapy. Tohoku J Exp Med. 2005;206:347-352.

15. Eisner MD, Iribarren C, Yelin EH, et al. Pulmonary function and the risk of functional limitation in chronic obstructive pulmonary disease. Am J Epidemiol. 2008;167:1090-1101.

16. Blanc PD, Iribarren C, Trupin L, et al. Occupational exposures and the risk of COPD: dusty trades revisited. Thorax. 2009;64:6-12.

17. Omachi TA, Katz PP, Yelin EH, et al. Depression and health-related quality of life in chronic obstructive pulmonary disease. Am J Med. 2009;122:778.e9-e15.

18. Sidney S, Sorel M, Quesenberry CP Jr, DeLuise C, Lanes S, Eisner MD. COPD and incident cardiovascular disease hospitalizations and mortality: Kaiser Permanente Medical Care Program. Chest. 2005;128:2068-2075.

19. Eisner MD, Yelin EH, Trupin L, Blanc PD. The influence of chronic respiratory conditions on health status and work disability. Am J Public Health. 2002;92:1506-1513.

20. Cigarette smoking among adults - United States, 1997. MMWR Morb Mortl Wkly Rep. 1999;48:993-996.

21. National Health Interview Survey. Accessed March 28, 2008, at http://www.cdc.gov/nchs/about/major/nhis/quest_data_related_1997_ forward.htm.

22. American Thoracic Society. Standardization of spirometry - 1987 update. Statement of the American Thoracic Society. Am Rev Respir Dis. 1987;136:1285-1298.

23. Standardization of Spirometry, 1994 Update. American Thoracic Society. Am J Respir Crit Care Med. 1995;152:1107-1136.

24. Walters JA, Wood-Baker R, Walls J, Johns DP. Stability of the EasyOne ultrasonic spirometer for use in general practice. Respirology. 2006;11: 306-310.

25. Perez-Padilla R, Vazquez-Garcia JC, Marquez MN, et al. The longterm stability of portable spirometers used in a multinational study of the prevalence of chronic obstructive pulmonary disease. Respir Care. 2006;51:1167-1171.

26. Eisner MD, Trupin L, Katz PP, et al. Development and validation of a survey-based COPD severity score. Chest. 2005;127:1890-1897.

27. Omachi TA, Yelin EH, Katz PP, Blanc PD, Eisner MD. The COPD Severity Score: a dynamic prediction tool for health care utilization. COPD. 2008;5:339-346.

28. Celli BR, Cote CG, Marin JM, et al. The body-mass index, airflow obstruction, dyspnea, and exercise capacity index in chronic obstructive pulmonary disease. $N$ Engl J Med. 2004;350:1005-1012.

29. Martinez FJ, Han MK, Andrei AC, et al. Longitudinal change in the BODE index predicts mortality in severe emphysema. Am J Respir Crit Care Med. 2008;178:491-499. 
30. Ong KC, Lu SJ, Soh CS. Does the multidimensional grading system (BODE) correspond to differences in health status of patients with COPD? Int J Chron Obstruct Pulmon Dis. 2006;1:91-96.

31. McDowell I, Newell C. Measuring health: A guide to rating scales and questionnaires. New York: Oxford University Press; 1996.

32. Folstein MF, Folstein SE, McHugh PR. "Mini-mental state". A practical method for grading the cognitive state of patients for the clinician. J Psychiatr Res. 1975;12:189-198.

33. Molloy DW, Alemayehu E, Roberts R. Reliability of a Standardized Mini-Mental State Examination compared with the traditional MiniMental State Examination. Am J Psychiatry. 1991;148:102-105.

34. Fillenbaum GG, Heyman A, Wilkinson WE, Haynes CS. Comparison of two screening tests in Alzheimer's disease. The correlation and reliability of the Mini-Mental State Examination and the modified Blessed test. Arch Neurol. 1987;44:924-927.

35. Faustman WO, Moses JA Jr, Csernansky JG. Limitations of the MiniMental State Examination in predicting neuropsychological functioning in a psychiatric sample. Acta Psychiatr Scand. 1990;81:126-131.

36. Mitrushina M, Satz P. Reliability and validity of the Mini-Mental State Exam in neurologically intact elderly. J Clin Psychol. 1991;47: 537-543.

37. Rait G, Fletcher A, Smeeth L, et al. Prevalence of cognitive impairment: results from the MRC trial of assessment and management of older people in the community. Age Ageing. 2005;34:242-248.

38. Norman GR, Sloan JA, Wyrwich KW. Interpretation of changes in health-related quality of life: The remarkable universality of half a standard deviation. Med Care. 2003;41:582-592.
39. Curtis LH, Hammill BG, Eisenstein EL, Kramer JM, Anstrom KJ. Using inverse probability-weighted estimators in comparative effectiveness analyses with observational databases. Med Care. 2007;45: S103-S107.

40. Cleveland WS. Robust locally weighted regression and smoothing scatterplots. J Am Stat Assoc. 1979;74:829-836.

41. Liesker JJ, Postma DS, Beukema RJ, et al. Cognitive performance in patients with COPD. Respir Med. 2004;98:351-356.

42. Incalzil RA, Bellia V, Maggi S, et al. Mild to moderate chronic airways disease does not carry an excess risk of cognitive dysfunction. Aging Clin Exp Res. 2002;14:395-401.

43. Perneczky R, Pohl C, Sorg C, et al. Impairment of activities of daily living requiring memory or complex reasoning as part of the MCI syndrome. Int J Geriatr Psychiatry. 2006;21:158-162.

44. Kukull WA, Larson EB, Teri L, Bowen J, McCormick W, Pfanschmidt ML. The Mini-Mental State Examination score and the clinical diagnosis of dementia. J Clin Epidemiol. 1994;47:1061-1067.

45. Kaufer DI, Williams CS, Braaten AJ, Gill K, Zimmerman S, Sloane PD. Cognitive screening for dementia and mild cognitive impairment in assisted living: Comparison of 3 tests. J Am Med Dir Assoc. 2008;9: 586-593.

46. Eisner MD, Balmes J, Katz PP, Trupin L, Yelin EH, Blanc PD. Lifetime environmental tobacco smoke exposure and the risk of chronic obstructive pulmonary disease. Environ Health. 2005;4:7.

47. Mannino DM, Homa DM, Akinbami LJ, Ford ES, Redd SC. Chronic obstructive pulmonary disease surveillance - United States, 1971-2000. MMWR Surveill Summ. 2002;51:1-16.
International Journal of COPD

\section{Publish your work in this journal}

The International Journal of COPD is an international, peer-reviewed journal of therapeutics and pharmacology focusing on concise rapid reporting of clinical studies and reviews in COPD. Special focus is given to the pathophysiological processes underlying the disease, intervention programs, patient focused education, and self management protocols.

\section{Dovepress}

This journal is indexed on PubMed Central, MedLine and CAS. The manuscript management system is completely online and includes a very quick and fair peer-review system, which is all easy to use. Visit http://www.dovepress.com/testimonials.php to read real quotes from published authors. 